\title{
CYTOCHROME P450 CYP1B1*2 GENE AND ITS ASSOCIATION WITH T2D IN TABUK POPULATION, NORTHWESTERN REGION OF SAUDI ARABIA
}

\author{
IMADELDIN ELFAKI ${ }^{1 *}$, FAHAD M ALMUTAIRI ${ }^{1 *}$, RASHID MIR $^{2}$, ROAID KHAN ${ }^{3}$, FAISEL ABU-DUHIER ${ }^{2}$
}

\begin{abstract}
${ }^{1}$ Department of Biochemistry, Faculty of Science, University of Tabuk, Kingdom of Saudi Arabia. ${ }^{2}$ Department of Medical Lab Technology Faculty of Applied Medical Sciences, University of Tabuk, Kingdom of Saudi Arabia. ${ }^{3}$ Department of Endocrinology, King Salman Armed Forces Hospital, Tabuk, Kingdom of Saudi Arabia. Email: ielfaki@ut.edu.sa/falrabae@ut.edu.sa
\end{abstract}

Received: 27 July 2017, Revised and Accepted: 25 September 2017

ABSTRACT

Objective: Cytochrome P450 1B1 (CYP1B1) is involved in the activation of procarcinogens and steroid metabolism. Genetic variants of CYP1B1 are associated with altered catalytic activity and disease phenotypes. The purpose of this study was to investigate the role of CYP1B1 (rs1056827) polymorphism in inducing T2D.

Methods: This cross-sectional study enrolled 113 subjects of T2D and 120 controls. DNA was isolated from blood. Genotyping of the rs1056827 was done by allele-specific polymerase chain reaction. The frequency of alleles and genotype distribution was compared in T2D cases and healthy controls. Statistical analysis was performed with SPSS, Chi-square, and Fisher exact test. Hardy-Weinberg equilibrium was tested by a $\chi^{2}$ test. The associations between rs1056827 variant genotypes and T2D were estimated by computing the odds ratios and their 95\% confidence intervals (CI) from univariate and multivariate logistic regression analysis.

Results: A significant association of rs1056827 was found between T2D cases and controls (p<0.0001). When GG genotype was compared with GT genotype a significant association was found with odd ration (OD)0.24 (95\% CI: (0.131-0.452) and risk ratio (RR) 0.45 (0.30-0.67) times the risk of T2D heterozygous with the $\mathrm{G} / \mathrm{T}$ allele $(\mathrm{p} \leq 0.0002)$. In a comparison of GG homozygous with the TT homozygous, there was no significant association with the OD 0.38 (95\% CI: (0.02-6.51) RR 0.55(0.13-2.35), p<0.49. When G allele was compared with the T allele a highly significant association with OD 0.54 (95\% [CI]: $(0.37-0.80)$ RR $0.75(0.630-0.897)<\mathrm{p} \leq 0.003$ suggesting a possible dominant effect of this polymorphism on T2D risk.

Conclusion: This result suggests a significant association between rs1056827G $>$ T polymorphism and T2D. This finding is limited due to the smaller sample size and can be validated by large sample size studies.

Keywords: CYP1B1rs1056827G>T, Type 2 diabetes (T2D), Single nucleotide polymorphisms, Cytochrome P450, CYP1B1 allelic variants, Allelespecific polymerase chain reaction.

(C) 2018 The Authors. Published by Innovare Academic Sciences Pvt Ltd. This is an open access article under the CC BY license (http://creativecommons. org/licenses/by/4. 0/) DOI: http://dx.doi.org/10.22159/ajpcr.2018.v11i1.21657

\section{INTRODUCTION}

Human CYPs are membrane-bound proteins located to the mitochondria or the endoplasmic reticulum [1]. The cytochromes P450 (CYPs) are the major superfamily of the enzyme catalyzing the oxidative biotransformation of lipophilic xenobiotics including drugs [2]. This superfamily consists of 57 CYP genes and 58 pseudogenes [3]. Most of the CYPs genes in human are grouped according to the similarity of the amino acids sequence into 18 families and 44 subfamilies [2]. In addition to their role in metabolizing the xenobiotics, they have specific endogenous functions, as they are involved in the biosynthesis of steroid hormones, prostaglandins, bile acids, Vitamin D3, and others [2]. Genetic polymorphisms of CYPs influence the metabolism of their drugs substrate. Influencing the drug metabolism may lead to an adverse drug reaction, or inter-individual variation in drug response [4,5]. Most members of the CYP families are polymorphic. The most common genetic mutation in human CYP genes is singlenucleotide polymorphisms (SNPs) that may change the amino acid in the corresponding CYP protein [6]. This change in the amino acids sequences of the protein may alter its expression, or the catalytic activity, which may induce diseases as a phenotype [6]. The crystal structure of the CYP1B1 was determined [7], it has a narrow slot-like active site that is similar to that of CYP1A1; however, the residues around the edge of the active sites are different for specific binding of substrates and inhibitors [7]. Using the reverse transcriptase-coupled polymerase chain reaction (RT-PCR), CYP1B1 mRNA was detected in hepatocytes, lymphocytes, and uterus [8]. CYP1B1 gene is expressed in different amount among tissues, the highest mRNA expression levels were found in extrahepatic tissues such as renal, uterine, heart, brain, lung, and skeletal muscle [9].

CYP1B1 is highly expressed in estrogen-related organ such as uterus, ovaries, and mammary glands [10]. The CYP1B1 catalyzes the metabolism of endogenous substrates such as $17 \beta$-estradiol into reactive metabolites, such as 4-hydroxyestradiol [11]. The 4-hydroxyestradiol, a catechol metabolite reduces the activity of estrogen. However, it generates free radicals from the reductive-oxidative cycling with the corresponding quinone and semiquinone forms, which cause cellular damage. Therefore, 4-hydroxyestradiol is toxicologically active and may have a role in the induction of cancer [12]. The 4-hydroxyestradiol level is elevated in human uterine and breast cancers in comparison to normal tissue [12]. Mutations in CYP1B1 were reported to be causes of disease phenotype such as the primary congenital glaucoma [13]. Moreover, CYP1B1 gene polymorphisms L432V and A119S (rs1056827) increase the risk of developing endometrial [14] and laryngeal cancers [15], respectively. It has been reported that CYP2C8*3 (rs10509681), CYP2C9*2 (rs1799853), CYP3A4 (Ile118Val), and CYP2C19*2 polymorphisms were associated with increased susceptibility to T2D in Indian, Japanese, and Mexican populations, respectively [16-18].

In Kingdom of Saudi Arabia (KSA), the prevalence of DM in adult was estimated to be $23.7 \%$ in 2004 [19]. Recently, it was reported that in 
Jeddah, KSA, about $50 \%$ of the subjects aging 50 years or more are types 2 diabetic, whereas, $10-15 \%$ from the remainders are pre-diabetics [20]. Apart from the short- and long-term complications of DM [21], there is the economic burden of the disease [22]. It is widely accepted that T2D is a multifactorial develop from interaction of risk alleles, behavioral and environmental factors [23] and lifestyle [24]. In the present study, it was examined the frequency of the CYPs1B1 (rs1056827) (Fig. 1) in 120 healthy control and 113 T2D patients of Tabuk population.

\section{METHODS}

\section{Study population}

The study was approved by the Research Committee of Armed forces hospitals, Northwestern region, Tabuk. It included two groups consisted of 120 healthy controls and 113 T2D patients visiting armed forces hospitals, Northwestern region and King Fahad Specialist Hospitals Tabuk, for routine check-up dung the period from January to June 2017. The study was conducted in the Department of Biochemistry, Faculty of Science in collaboration with Prince Fahd Bin Sultan Research Chair, Department of Medical Lab Technology, Faculty of Applied Medical Sciences, University of Tabuk, KSA.

\section{DNA extraction}

Peripheral blood samples were collected in EDTA vials from the T2D patients, or from the healthy controls. Genomic DNA from blood was isolated using DNA extraction kit (QIAamp DNA Blood Mini Kit 51106, Qiagen, Germany). The quality and integrity of isolate genomic DNA were checked by NanoDrop ${ }^{\mathrm{TM}}$ (Thermo Scientific, USA). The isolated DNA was stored at $-20^{\circ} \mathrm{C}$ until further use.

\section{Allele-specific PCR for CYP1B1*2 codon 119 (Ala119Ser) (rs1056827, 119G $>$ T) gene}

The genomic DNA genotypes were analyzed using single tube multiplex PCR assay which was performed in a reaction volume of $25 \mu \mathrm{L}$ containing template DNA (50 ng), $0.2 \mu \mathrm{M}$ of each primers which were designed by the primer 3 software listed in Table 1 and $12.5 \mu \mathrm{L}$ from GoTaq ${ }^{\circledR}$ Green Master Mix (cat no M7122, Promega, USA) that is composed of GoTaq ${ }^{\circledR}$ DNA Polymerase, $2 X$ Green GoTaq® Reaction Buffer (pH 8.5), $400 \mu \mathrm{M}$ dATP, $400 \mu \mathrm{M}$ dGTP, $400 \mu \mathrm{M} \mathrm{dCTP}, 400 \mu \mathrm{M}$ dTTP, and $3 \mathrm{mM} \mathrm{MgCl} 2$. Final volume of $25 \mu \mathrm{L}$ was adjusted by adding nuclease-free $\mathrm{ddH}_{2} \mathrm{O}$.

\section{Thermocycling conditions}

The reaction mixture was subjected to initial denaturation at $95^{\circ} \mathrm{C}$ for $10 \mathrm{~min}$, followed by 40 cycles of $94^{\circ} \mathrm{C}$ for $30 \mathrm{~s}, 56^{\circ} \mathrm{C}$ for $35 \mathrm{~s}$, and $72^{\circ} \mathrm{C}$ for $35 \mathrm{~s}$ with a final extension of $72^{\circ} \mathrm{C}$ for $10 \mathrm{~min}$.

\section{Statistical analysis}

T2D patients and controls were compared by statistical analysis performed using the SPSS 16.0 software package. Chi-square analysis and Fisher exact test were carried out to compare CYP1B1*2 ( rs1056827G>T) frequency with several clinical aspects, including sex and age. HardyWeinberg equilibrium was tested by a $\chi^{2}$ test to compare the observed genotype frequencies within the case-control groups. The associations between CYP1B1*2 (rs1056827G>C) variant genotypes and risk of T2D were estimated by computing the odds ratios (ORs) and their $95 \%$ confidence intervals (CIs) from both univariate and multivariate logistic regression analysis. $\mathrm{p} \leq 0.05$ was considered statistically significant.

\section{RESULTS}

\section{CYP1B1 (rs1056827G $>$ T) genotyping}

CYPs1B1 (rs1056827G>T) genotyping was analyzed by allele-specific PCR. The PCR products were separated on a $2 \%$ agarose gel stained with ethidium bromide. Both of the alleles $\mathrm{G}$ homozygote and $\mathrm{T}$ homozygote generated a single fragment of $203 \mathrm{bp}$ as shown in Fig. 2.

Allelic frequencies and genotype distribution of CYP1B1*2 rs1056827 G>T

The association of CYP1B1*2 rs1056827 gene polymorphism between cases and controls is summarized in Table 2 . The result of this study indicated that there was a high percentage of GG genotype (43.36\%) in patients compared to $15.83 \%$ in the controls (Table 2). The frequency of the GT genotypes was $55.75 \%$ in the patients group, whereas it was $83.33 \%$ in the control group (Table 2). This study revealed the same percentage of TT genotype $(<1 \%)$ in both patients as well as controls. The observed genotype frequencies of CYP1B1*2 (GG, GT, and TT) were statistically significantly different among patients and healthy controls $\left(\chi^{2}=20, p=0.0001\right)$ (Table 2).

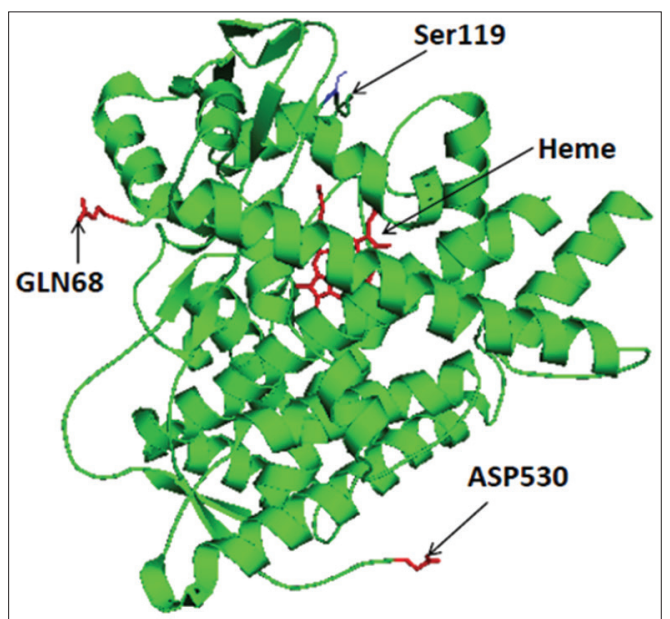

Fig. 1: Three-dimensional structure of the CYP1B1 (PDB ID: 3PM0) The gene polymorphism of the rs 1056827 results in a change of the amino acid residue 119 from alanine (Ala) to serine (Ser). The Ser119 (the site of polymorphism) is illustrated in blue color. The heme group, $\mathrm{N}$-terminal glutamine, and $\mathrm{C}$-terminal aspartic acid residues are illustrated in red color. This figure has been prepared using PYMOL

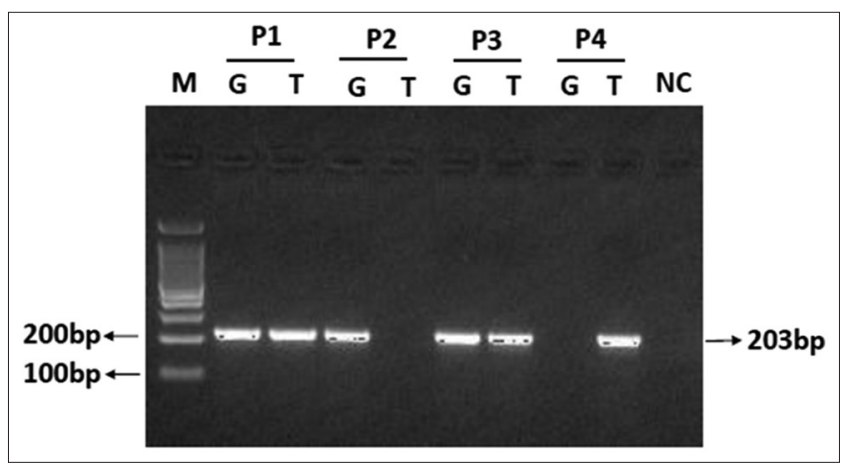

Fig. 2: Agarose gel electrophoresis of allele-specific PCR for the CYP1B1 *2 rs1056827 G $>$ T codon 119 (Ala119Ser), rs1056827 $119 \mathrm{G}>\mathrm{T}$ gene polymorphism in controls and cases. M- 100bp DNA ladder, $\mathrm{P} 1$ and $\mathrm{P} 3$ heterozygous (both $\mathrm{G}$ and $\mathrm{T}$ are present), P2- homozygous for G genotype, P4 homozygous for T genotype, and NC-negative control

Table 1: Primers used for CYP1B1*2 (r1056827 G>C) genotype analysis

Allele-specific PCR primer for CC genotype

Wild type reverse 5'-ACACGGAAGGAGGCGAAGAC-3' 203bp

primer

Common forward $\quad$ '-CCACTGATCGGAAACGC-3'

primer

Allele-specific PCR primer for AA genotype

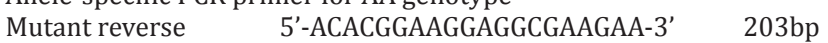

primer

Common forward 5'-CCACTGATCGGAAACGC-3

primer 
Table 2: Association of genotype frequencies of CYP1B1 $* 2$ rs 1056827 gene between cases and controls

\begin{tabular}{llllllll}
\hline Subjects & N & GG Genotype & TT Genotype & G/T Genotype & $\chi 2$ & df & $\boldsymbol{P}$-value \\
\hline Cases & 113 & $49(43.36)$ & $1(0.88)$ & $63(55.75)$ & 20 & 2 & 0.0001 \\
Controls & 120 & $19(15.83)$ & $1(0.83)$ & $100(83.33)$ & & & \\
\hline
\end{tabular}

The higher frequency of $\mathrm{G}$ allele was observed in cases than the healthy controls ( $\mathrm{fG}=0.71$ vs. 0.57 ). In controls the higher frequency of $\mathrm{T}$ allele was reported that the cases (fT $=0.43$ vs. 0.29 ) as summarized in Table 3.

Risk of T2D is associated with the CYPs1b1 rs1056827 G>T variant Odds ratio (OD) and risk ratio (RR) with 95\% CI were calculated for each group to estimate the degree of association between the CYP1B1*2 rs1056827G $>$ T variant and risk of T2D risk in Saudi patients as depicted in (Table 4). When it was compared the GG homozygous genotype with the TT homozygous genotype, we did not find a significant association with the OR $0.38(0.02-6.51)$ RR $0.45(0.30-$ $0.67) \mathrm{p}<0.49$. In a comparison of GG homozygous genotype with the GT heterozygous genotype, it was found a highly significant association with the OR $0.24(0.131-0.45)$ RR 0.45(0.30-0.67) ( $\mathrm{p} \leq 0.0002)$. During the allelic comparison, the $G$ allele was compared with the $T$ allele, and it was found a highly significant association with OR $0.54(0.37-0.80)$ and RR $0.75(0.63-0.897) \mathrm{p} \leq 0.003$ indicating a possible dominant effect of this polymorphism on T2D risk (Table 4).

When CYP1B1*2 rs1056827 polymorphism was investigated the heterozygous carriers of the rs1056827 SNP were more likely to develop T2D compared to their wild-type counterparts OR 0.24 (0.131$0.45)$ RR $0.45(0.30-0.67)(p \leq 0.0002)$ (Table 4). The combination of being homozygote for rs1056827 SNPs did not appear to be at an increase risk of disease. The present study demonstrates that the CYP1B1*2 rs1056827 gene polymorphism (heterozygosity) may contribute to the risk of developing T2D in Saudi population of Tabuk region. The individuals who were carrying GG genotype (homozygous) of rs $1056827 \mathrm{G}>\mathrm{T}$ were not associated with an increased risk of T2D disease.

\section{DISCUSSION}

This study examines the potential influence of CYP1B $1 * 2$ (rs1056827G $>\mathrm{T}$ ) genetic variants on T2D risk. The CYP1B1*2 rs1056827 heterozygosity appeared to be associated with increasing risk of developing T2D in Saudi population. CYP1B1 is a major enzyme involved in the hydroxylation of estrogens and activation of potential carcinogens [25] and is regulated by several key transcriptional factors, including aryl hydrocarbon receptor and estrogen receptor [26]. It has been reported that CYP1B1 expression increases in the early phase of in vitro adipogenic differentiation in parallel with peroxisome proliferative activated receptor gamma (PPAR gamma) expression in tissue $[27,28]$. PPAR gamma is an important transcriptional factor for adipocyte differentiation and glucose homeostasis [29]. In CYP1B1 KO mice, the expression of PPAR gamma was reduced at both mRNA and protein levels in adipose tissues as well as liver [28]. The same study demonstrated that the CYP1B1 KO mice exhibited improved glucose intolerance than the wild-type mice [28]. This may be the reason why the highly active CYP1B1*2 rs1056827 [30] may the cause of induction of T2D in the GT genotype carriers.

In addition, the role of the CYP1B1 in the occurrence of obesity and glucose intolerance and hence insulin resistance can be attributed to other effects. It has been reported that in the liver and fat tissues of CYP1B1 deficient mice there were suppression of genes that promote lipogenesis [28]. For instance, the expression of the gene of Acetyl CoA carboxylase that catalyzes the synthesis of malonyl-CoA, a key step fatty acids synthesis is reduced [31]. There will also be decreased expression of fatty acid synthase, an important a multi-enzyme protein that catalyzes synthesis of fatty acids [28]. The expression of gene of the Stearoyl-CoA desaturase- 1 that catalyzes monounsaturated fatty acids
Table 3: Allele frequencies of CYP1B1*2 rs1056827 gene polymorphism among cases and controls

\begin{tabular}{llllllll}
\hline Subjects & Number & GG & TT & G/T & G allele & T allele & $\mathbf{p ~ v a l u e ~}$ \\
\hline Cases & 113 & 49 & 01 & 63 & 0.71 & 0.29 & 0.0001 \\
Controls & 120 & 19 & 01 & 100 & 0.57 & 0.43 & \\
Total & 233 & 68 & 02 & 163 & & & \\
\hline
\end{tabular}

synthesis is decreased [28]. Furthermore, in the CYP1B1 KO mice, there was enhancement of expression of the genes that increase lipolysis [28], the carnitine palmitoyltransferase $1 \mathrm{a}$ and the uncoupling protein 2 which both promotes mitochondrial fatty acid beta-oxidation [28]. Therefore, the highly active version [30] of CYP1B1*2 rs5610827 can be a cause of T2D as indicated in this study results.

The major phenotypic features associated with CYP1B1 deletion include protection from the deleterious effects of excess dietary fat, including oxidative stress, hepatic steatosis, and T2D [32]. Recently microarray data from the livers of the CYP1B1 KO mice that are resistant to diet-induced obesity indicated that CYP1B1 deletion substantially alters the expression of genes associated with fatty acid homeostasis [33]. Several studies have examined the relationship between individual CYP1B1 polymorphisms and cancer risk [14,15,34-37]. However, very limited data are available for CYP1B1*2 (rs1056827G>T) genetic variants in T2D. The aim of the current study was the investigation of allelic distribution of CYP1B1*2 (rs1056827G>T) genetic variants in an ethnically-homogeneous population of controls and patients with one of the most frequently observed diseases in Saudi Arabia $[20,22,38]$. The effects of the CYP1B1*2 (rs1056827G $>$ T) genetic variants appear to be modest (Table 4). The variants in codons 119 of CYP1B1*2 (rs1056827) were associated with different substrate specificities and consequently the catalytic activity of the enzyme [39]. Several studies have been given an evidence that the CYP1B1 variants codons 119 of CYP1B1*2 rs1056827 exhibit greater catalytic 4-hydoxylation activity than the wild-type enzyme $[30,40]$. This may give a functional evidence as to why there appears to be an, albeit small, association with the risk of developing T2D in GT carriers.

Allelic frequencies of CYP1B1*2 rs1056827G $>$ T genetic variants in different cases in different populations

Several population-based studies have reported the frequency of CYP1B1*2 rs1056827G>T gene polymorphism in different populations. The distribution of CYP1B1*2 rs1056827G $>$ T genotypes varies among different ethnic groups with different diseases (Table 5). The range of GT genotypes frequency reported in different cases of different populations was in the range from $26 \%$ to $70 \%$. The TT genotypes of CYP1B1*2 rs1056827 polymorphism were ranged from $1 \%$ to $13 \%$ except in Iranian population (Table 5). The prevalence of GG genotypes of CYP1B1*2 rs1056827 polymorphism is ranged from 20 to $54 \%$. In this study, the prevalence of GG, TT, and GT genotypes in cases was $43 \%$, $1 \%$, and $56 \%$. Therefore, results were in accordance with the result of the other populations (Table 5).

Allelic frequencies of CYP1B1 $* 2$ (rs1056827G $>T$ ) genetic variants in control populations

Several population-based studies have reported a prevalence of CYP1B1*2 rs1056827G>T gene polymorphism in healthy controls of different populations (Table 5). The prevalence of GG, TT, and GT genotypes of CYP1B1*2 rs1056827 G>T in different populations is ranging from $43 \%$ to $79 \%, 0 \%$ to $23 \%$, and $16 \%$ to $55 \%$, respectively. In this study, the prevalence of GG, TT, and GT genotypes of CYP1B1*2 
Table 4: Risk of T2D is associated with the CYPs1b1 (rs1056827) G>T variant

\begin{tabular}{|c|c|c|c|c|c|}
\hline \multirow[t]{2}{*}{ Genotype } & \multirow{2}{*}{$\begin{array}{l}\text { T2D patients } \\
n=113(\%)\end{array}$} & \multirow{2}{*}{$\begin{array}{l}\text { Healthy controls } \\
\mathrm{n}=120(\%)\end{array}$} & \multirow[t]{2}{*}{ OR (95\% CI) } & \multirow[t]{2}{*}{$\mathbf{R R}$} & \multirow[t]{2}{*}{ p value } \\
\hline & & & & & \\
\hline CYPs1B1-GG & $49(43.36)$ & $19(15.33)$ & 1 (ref.) & 1 (ref.) & \\
\hline CYPs1B1-TT & $01(0.88)$ & $01(0.83)$ & $0.38(0.02-6.51)$ & $0.55(0.13-2.35)$ & $<0.49$ \\
\hline CYPs1B1 (GT+TT) & 64 & 101 & $0.24(0.13-0.45)$ & $0.45(0.30-0.68)$ & $<0.0003$ \\
\hline CYPs1B1-GG & 161 & 138 & 1 (ref.) & 1 (ref.) & \\
\hline CYPs1B1-TT & 65 & 102 & $0.54(0.37-0.80)$ & $0.75(0.63-0.897)$ & $\mathrm{p} \leq 0.003$ \\
\hline
\end{tabular}

Table 5: Frequency of CYP1B1*2 rs1056827 gene polymorphism in different populations

\begin{tabular}{|c|c|c|c|c|c|c|c|c|c|c|}
\hline \multirow[t]{2}{*}{ Country } & \multicolumn{5}{|c|}{ Controls } & \multicolumn{5}{|c|}{ Cases } \\
\hline & Year & $N=$ & GG \% & TT \% & G/T \% & $\mathbf{N}=$ & GG \% & TT \% & G/T \% & Reference \\
\hline Iran & 2017 & 79 & $48(60.8)$ & $18(22.8)$ & $13(16.4)$ & 79 & $16(20.3)$ & $42(53.2)$ & $21(26.5)$ & Afzali et al. [41] \\
\hline China & 2015 & 300 & $129(43)$ & $6(2)$ & $165(55)$ & 300 & $83(27.7)$ & $8(2.7)$ & $209(69.6)$ & Yu et al. [15] \\
\hline Australia & 2010 & 597 & $277(46.4)$ & $61(10.2)$ & $259(43.4)$ & 597 & $249(41.7)$ & $77(12.9)$ & $271(45.4)$ & Trubicka et al. [37] \\
\hline Bulgaria & 2015 & 257 & $129(50.2)$ & $20(7.8)$ & $108(42)$ & 229 & $104(45.4)$ & $22(9.6)$ & $103(45)$ & Kachakova et al. [35] \\
\hline South Korea & 2014 & 480 & $266(55.4)$ & $28(5.8)$ & $186(38.8)$ & 403 & $216(53.6)$ & $35(8.7)$ & $152(37.7)$ & Chang et al. [34] \\
\hline Chinese & 2014 & 300 & $236(78.7)$ & $0(0)$ & $64(21.3)$ & 300 & $154(51.3)$ & $16(5.4)$ & $130(43.3)$ & Shen et al. [36] \\
\hline This study & 2017 & 120 & $19(15.83)$ & $1(0.83)$ & $100(88)$ & 113 & $49(43)$ & $1(0.88)$ & $63(56)$ & \\
\hline
\end{tabular}

(rs1056827) gene polymorphism is about $16 \%,<1 \%$, and $83 \%$, respectively (Table 5)

Limited data exist about status of CYP1B1*2 rs1056827 polymorphism among patients with T2D especially among the population of Northwestern region of Saudi Arabia.

\section{CONCLUSION}

The CYP1B1 variants examined in this study suggest that CYP1B1*2 (rs1056827) contribute to inter-individual differences in T2D risk and may be potentially valuable in genetic risk assessment. This finding may have potentially important implications for genetic risk assessment and prevention studies. However, it is important to be confirmed in other T2D populations before introducing it in the clinical setting.

\section{ACKNOWLEDGMENT}

We are very grateful to all participants who have provided blood samples for this project. This study was funded by the University of Tabuk, Deanship of Scientific Research for IE and FMA (Grant for project No S-1437-0178).

\section{REFERENCES}

1. Knockaert L, Fromenty B, Robin MA. Mechanisms of mitochondrial targeting of cytochrome P450 2E1: Physiopathological role in liver injury and obesity. FEBS J 2011;278:4252-60.

2. Zanger UM, Schwab M. Cytochrome P450 enzymes in drug metabolism: Regulation of gene expression, enzyme activities, and impact of genetic variation. Pharmacol Ther 2013;138:103-41.

3. Nelson DR, Zeldin DC, Hoffman SM, Maltais LJ, Wain HM, Nebert DW. Comparison of cytochrome P450 (CYP) genes from the mouse and human genomes, including nomenclature recommendations for genes, pseudogenes and alternative-splice variants. Pharmacogenetics 2004;14:1-18.

4. Ingelman-Sundberg M. Genetic polymorphisms of cytochrome P450 2D6 (CYP2D6): Clinical consequences, evolutionary aspects and functional diversity. Pharmacogenomics J 2005;5:6-13

5. Kirchheiner J, Nickchen K, Bauer M, Wong ML, Licinio J, Roots I, et al. Pharmacogenetics of antidepressants and antipsychotics: The contribution of allelic variations to the phenotype of drug response. Mol Psychiatry 2004;9:442-73.

6. Zhou SF, Liu JP, Chowbay B. Polymorphism of human cytochrome P450 enzymes and its clinical impact. Drug Metab Rev 2009;41:89295.
7. Wang A, Savas U, Stout CD, Johnson EF. Structural characterization of the complex between alpha-naphthoflavone and human cytochrome P450 1B1. J Biol Chem 2011;286:5736-43.

8. Hakkola J, Pasanen M, Pelkonen O, Hukkanen J, Evisalmi S, Anttila S, et al. Expression of CYP1B1 in human adult and fetal tissues and differential inducibility of CYP1B1 and CYP1A1 by Ah receptor ligands in human placenta and cultured cells. Carcinogenesis 1997:18:391-7.

9. Pavek P, Dvorak Z. Xenobiotic-induced transcriptional regulation of xenobiotic metabolizing enzymes of the cytochrome P450 superfamily in human extrahepatic tissues. Curr Drug Metab 2008;9:129-43.

10. Tsuchiya Y, Nakajima M, Kyo S, Kanaya T, Inoue M, Yokoi T. Human CYP1B1 is regulated by estradiol via estrogen receptor. Cancer Res 2004:64:3119-25.

11. Smerdová L, Šmerdová J, Kabátková M, Kohoutek J, Blažek D, Machala M, et al. Upregulation of CYP1B1 expression by inflammatory cytokines is mediated by the p38 MAP kinase signal transduction pathway. Carcinogenesis 2014;35:2534-43.

12. Bolton JL, Thatcher GR. Potential mechanisms of estrogen quinone carcinogenesis. Chem Res Toxicol 2008;21:93-101.

13. Badeeb OM, Micheal S, Koenekoop RK, den Hollander AI, Hedrawi MT. CYP1B1 mutations in patients with primary congenital glaucoma from Saudi Arabia. BMC Med Genet 2014;15:109.

14. Zhu ZY, Mu YQ, Fu XM, Li SM, Zhao FX. Association of CYP1B1 gene polymorphisms and the positive expression of estrogen alpha and estrogen beta with endometrial cancer risk. Eur J Gynaecol Oncol 2011;32:188-91.

15. Yu PJ, Chen WG, Feng QL, Chen W, Jiang MJ, Li ZQ. Association between CYP1B1 gene polymorphisms and risk factors and susceptibility to laryngeal cancer. Med Sci Monit 2015;21:239-45.

16. Hoyo-Vadillo C, Garcia-Mena J, Valladares A, Venturelli CR, WacherRodarte N, Kumate J, et al. Association of CYP2C19 genotype with Type 2 diabetes. Health 2010;2:1184-90.

17. Mahdi F, Raza ST, Rizvi S, Abbas S, Karoli R. Distribution of genetic polymorphisms in drug metabolizing gene cytochrome $\mathrm{P} 450$ (CYP2C $8 * 3$ and CYP2C9*2) in a North Indian Type 2 diabetes population. Exploratory Res Hypothesis Med 2016;1:42-6.

18. Yamada Y, Matsuo H, Watanabe S, Kato K, Yajima K, Hibino T, et al. Association of a polymorphism of CYP3A4 with Type 2 diabetes mellitus. Int J Mol Med 2007;20:703-7

19. Al-Nozha MM, Al-Maatouq MA, Al-Mazrou YY, Al-Harthi SS, Arafah MR, Khalil MZ, et al. Diabetes mellitus in Saudi Arabia. Saudi Med J 2004;25:1603-10.

20. Bahijri SM, Jambi HA, Al Raddadi RM, Ferns G, Tuomilehto J. The prevalence of diabetes and prediabetes in the adult population of Jeddah, Saudi Arabia-a community-based survey. PLoS One 2016;11:e 0152559.

21. Prabhakar PK. Pathophysiology of secondary complications of diabetes millitus. Asian J Pharm Clin Res 2016;9:32-6. 
22. Alhowaish AK. Economic costs of diabetes in Saudi Arabia. J Family Community Med 2013;20:1-7

23. Murea M, Ma L, Freedman BI. Genetic and environmental factors associated with Type 2 diabetes and diabetic vascular complications. Rev Diabetes Stud 2012;9:6-22.

24. Andayani TM, Ibrahim MI, Asdie AH. The association of diabetes related factor and quality of life in Type 2 diabetes mellitus. Int J Pharm Pharm Sci 2010;2:139-45.

25. Gajjar K, Martin-Hirsch PL, Martin FL. CYP1B1 and hormone-induced cancer. Cancer Lett 2012;324:13-30.

26. Ahmed S, Valen E, Sandelin A, Matthews J. Dioxin increases the interaction between aryl hydrocarbon receptor and estrogen receptor alpha at human promoters. Toxicol Sci 2009;111:254-66.

27. Cho YC, Zheng W, Yamamoto M, Liu X, Hanlon PR, Jefcoate CR. Differentiation of pluripotent $\mathrm{C} 3 \mathrm{H} 10 \mathrm{~T} 1 / 2$ cells rapidly elevates CYP1B1 through a novel process that overcomes a loss of Ah Receptor. Arch Biochem Biophys 2005;439:139-53

28. Liu X, Huang T, Li L, Tang Y, Tian Y, Wang S, et al. CYP1B1 deficiency ameliorates obesity and glucose intolerance induced by high fat diet in adult C57BL/6J mice. Am J Transl Res 2015;7:761-71.

29. Jones JR, Barrick C, Kim KA, Lindner J, Blondeau B, Fujimoto Y, et al. Deletion of PPARgamma in adipose tissues of mice protects against high fat diet-induced obesity and insulin resistance. Proc Natl Acad Sci U S A 2005;102:6207-12.

30. Hanna IH, Dawling S, Roodi N, Guengerich FP, Parl FF. Cytochrome P450 1B1 (CYP1B1) pharmacogenetics: Association of polymorphisms with functional differences in estrogen hydroxylation activity. Cancer Res 2000;60:3440-4

31. Berg JM, Tymoczko JL, Stryer L. Biochemistry. $5^{\text {th }}$ ed. New York: WH Freeman; 2002.

32. Palenski TL, Gurel Z, Sorenson CM, Hankenson KD, Sheibani N. Cyp1B1 expression promotes angiogenesis by suppressing NF-?B activity. Am J Physiol Cell Physiol 2013;305:C1170-84

33. Larsen MC, Bushkofsky JR, Gorman T, Adhami V, Mukhtar H, Wang S, et al. Cytochrome P450 1B1: An unexpected modulator of liver fatty acid homeostasis. Arch Biochem Biophys 2015;571:21-39.

34. Chang I, Fukuhara S, Wong DK, Gill A, Mitsui Y, Majid S, et al. Cytochrome P450 1B1 polymorphisms and risk of renal cell carcinoma in men. Tumour Biol 2014;35:10223-30.

35. Kachakova D, Mitkova A, Popov E, Beltcheva O, Vlahova A, Dikov T, et al. Polymorphisms in androgen metabolism genes AR, CYP1B1, CYP19, and SRD5A2and prostate cancer risk and aggressiveness in Bulgarian patients. Turk J Med Sci 2016;46:626-40.

36. Shen Y, Xu Q, Ren M, Cai Y, Xu J. Role of single nucleotide polymorphisms in estrogen-metabolizing enzymes and susceptibility to uterine leiomyoma in Han Chinese: A case-control study. J Obstet Gynaecol Res 2014;40:1077-84

37. Trubicka J, Grabowska-Klujszo E, Suchy J, Masojc B, Serrano-Fernandez P, Kurzawski G, et al. Variant alleles of the CYP1B1 gene are associated with colorectal cancer susceptibility. BMC Cancer 2010;10:420.

38. Alqurashi KA, Aljabri KS, Bokhari SA. Prevalence of diabetes mellitus in a Saudi community. Ann Saudi Med 2011;31:19-23.

39. Van Emburgh $\mathrm{BO}, \mathrm{Hu} \mathrm{JJ}$, Levine EA, Mosley LJ, Perrier ND, Freimanis RI, et al. Polymorphisms in CYP1B1, GSTM1, GSTT1 and GSTP1, and susceptibility to breast cancer. Oncol Rep 2008;19:1311-21.

40. Aklillu E, Oscarson M, Hidestrand M, Leidvik B, Otter C, Ingelman-Sundberg M. Functional analysis of six different polymorphic CYP1B1 enzyme variants found in an Ethiopian population. Mol Pharmacol 2002;61:586-94.

41. Afzali FM, Fard ZT, Akbari ME. The effect of polymorphisms on the Ala 119 ser gene cytochrome P450 $1 \mathrm{~B} 1 * 2$ on the susceptibility of Iranian women to develop breast cancer. Int $\mathrm{J}$ Cancer Manage 2017; 10:e4042. 